\title{
Ventas de bebidas alcohólicas y mortalidad violenta en Rusia
}

\section{Beverage-specific alcohol sales and violent mortality in Russia}

\author{
| YURY EVGENY RAZVODOVSKY
}

| Grodno State Medical University, Belarus.

Enviar correspondencia a:

Yury Evgeny Razvodovsky.

Grodno State Medical University, Belarus.

230009, Grodno, str. Gorky 80, Belarus. E-mail: razvodovsky@tut.by

\section{RESUMEN}

Introducción: La elevada mortalidad debido a la violencia en Rusia en las últimas décadas ha atraido un interés considerable. Existe evidencia de que el consumo intensivo (binge drinking) de alcohol es un factor potencialmente importante para explicar esta mortalidad. Presuponemos que un alto consumo de vodka junto con un patrón de consumo intensivo da lugar a una estrecha relación entre las ventas de vodka y las tasas de mortalidad violenta en Rusia.

Objetivos y métodos: Para probar esta hipótesis, se analizaron a través de series temporales ARIMA las tendencias en las ventas de alcohol per cápita y tasas de mortalidad por causas externas en Rusia entre 1980 y 2005. Resultados: Los resultados del análisis indican que las tasas de mortalidad por violencia tienden a ser más sensible a los cambios en las ventas de vodka per cápita que a cambio en el nivel total de las ventas de alcohol. El análisis sugiere que un aumento de 1 litro en las ventas de vodka per cápita se traduciria en un aumento del $5 \%$ en la tasa de mortalidad por violencia, un $11,3 \%$ de los accidentes y lesiones, un 9,2\% en la tasa de suicidio, un 12,5\% en tasa de homicidios y un aumento del 21,9\% en la tasa de intoxicación etílica fatal.

Conclusión: Los resultados de este estudio proporcionan apoyo a la hipótesis de que el alcohol jugó un papel crucial en la fluctuación de la tasa de mortalidad violenta en Rusia en las últimas décadas. Asumiendo que beber vodka está normalmente asociado con episodios de intoxicación, estos resultados proporcionan evidencia adicional de que el binge drinking es un determinante importante de la crisis de mortalidad violenta en Rusia.

Palabras clave: venta de alcohol, mortalidad violenta, análisis de series temporales ARIMA, Rusia

\section{ABSTRACT}

Background: High violent mortality rate in Russia and its profound fluctuation over recent decades have attracted considerable interest. A mounting body of evidence points to the binge drinking pattern as a potentially important contributor to the violent mortality crisis in Russia. In line with this evidence, we assume that higher level of vodka consumption in conjunction with binge drinking pattern results in close aggregate-level association between vodka sales and violent mortality rates in Russia. Aims and Methods: To test this hypothesis, trends in beverage-specific alcohol sales per capita and mortality rates from external causes in Russia between 1980 and 2005 were analyzed by means of ARIMA time-series analysis. Results: Results of the analysis indicate that violent mortality rates tend to be more responsive to change in vodka sales per capita than to change in total level of alcohol sales. The analysis suggests that a 1-litre increase in vodka sales per capita would result in a $5 \%$ increase in violent mortality rate, an $11.3 \%$ increase in accidents and injuries mortality rate, a $9.2 \%$ increase in suicide rate, a $12.5 \%$ increase in homicide rate, and a $21.9 \%$ increase in fatal alcohol poisoning rate. Conclusion: Ihe outcomes of this study provide support for the hypothesis that alcohol played a crucial role in the fluctuation in violent mortality rate in Russia in recent decades. Assuming that drinking vodka is usually associated with intoxication episodes, these findings provide additional evidence that the binge drinking pattern is an important determinant of the violent mortality crisis in Russia.

Key Words: beverage-specific alcohol sales, violent mortality, ARIMA timeseries analysis, Russia. 


\section{INTRODUCTION}

A Icohol is among the major risk factors for burden of disease and mortality worldwide (Norström \& Skog, 2001; Rehm, Taylor \& Patra, 2006). There is a common belief that alcohol is implicated in the mortality crisis observed in many former Soviet republics since the collapse of the communist system (Leon, Chenet, Shkolnikov, Zakharov, Shapiro, Rakhmanova, Vassin \& McKee, 1997; Nemtsov \& Razvodovsky, 2008; Moskalewicz, Razvodovsky \& Wieczorek, 2009). In Russia, for example, it has been estimated that alcohol may be responsible for more than $30 \%$ of all deaths (Nemtsov, 2002), while one recent study suggests that $43 \%$ of all deaths of males in the 25-54 years age range were attributable to hazardous drinking (Leon, Saburova, Tomkins, Andreev, Kiyanov, McKee \& Shkolnikov, 2007). The high level of alcohol-related problems in this country is probably caused by a combination of the higher overall level of alcohol consumption and harmful drinking patterns. In particular, a drinking culture where spirits predominate, together with a drinking pattern characterized by episodic heavy (or binge) drinking, normally on an empty stomach, may be especially detrimental to health. A worldwide assessment of drinking patterns showed that Russia and other countries of the former Soviet Union had the most hazardous pattern of drinking (Rehm, Sulkowska, Manczuk, Boffeta, Powles, Popova \& Zatonski, 2007). Furthermore, the results of the population survey carried out in Archangelsk suggest that $61.9 \%$ of male and $25.7 \%$ of female industrial workers had a consumption pattern that was hazardous according to the AUDIT definition (Nilssen, Averina, Brenn, Brox, Kalinin \& Archipovski, 2005).

Alcohol is increasingly implicated in the fluctuation of death rates from external causes in Russia over recent decades. In particular, the results from recent time-series analysis suggest that changes in per capita consumption have a significant impact on violent mortality rates (Nemtsov \& Razvodovsky, 2008). The link between suicide, lethal violence and population drinking in Russia has been analyzed in a number of aggregate-level studies. It was highlighted that annual changes in alcohol consumption in Russia from 1959 to 1998 were positively and significantly associated with homicide rate, indicating that a 1-litre increase in alcohol consumption is expected to increase homicide rate by approximately $10 \%$ ( 9.35 for men and $8.9 \%$ for women) (Bye, 2008). Similarly, the effect of alcohol on suicide rates in Russia was positive and significant, implying that a 1-litre change in per capita consumption is associated with a change in overall suicide of $12 \%$ (13\% for men and 6\% for women) (Landberg, 2008).

Nevertheless, we should bear in mind potential limitations of these studies, for example, that the estimation of overall alcohol consumption is more vulnerable to bias than sales data (Nemtsov, 2000). There is growing evidence that beverage preference and the binge drinking pattern, i.e., excessive consumption of strong spirits, has resulted in quicker intoxication and higher levels of it, increasing the propensity for violent mortality (Razvodovsky, 2000, 2001; Pridemore \& Chamlin, 2006). This hypothesis is consistent with the findings from previous research highlighting the fact that violent mortality rates are more responsive to per capita changes in distilled spirits consumption than to changes in total level of consumption (Norström \& Rossov 1999; Razvodovsky, 2001). An analysis of time-series data for Belarus covering the period 1970-2005 revealed that a 1-litre increase in overall alcohol sales would result in a $6.2 \%$ increase in the accident mortality rate, a $4.8 \%$ increase in homicide rate, a $2.6 \%$ increase in suicide rate, and a $11.1 \%$ increase in fatal alcohol poisoning rate, while a 1-litre increase in vodka sales is expected to increase the number of deaths from accidents by $10.7 \%$, the number of homicides by $6.8 \%$, the number of suicides by $4.7 \%$ and the number of fatal alcohol poisonings by $14.6 \%$ (Razvodovsky, 2003). In line with these findings, we assume that higher levels of vodka consumption in conjunction with a binge drinking pattern results in a close aggregate-level association between vodka sales and violent mortality in Russia. To test this hypothesis, trends in beverage-specific alcohol sales per capita and violent mortality rates from 1980 to 2005 in Russia were analyzed employing ARIMA time-series analysis.

\section{MATERIAL AND METHODS}

The data on violent mortality rates per 100,000 residents are taken from the Russian vital statistics registration system. The data on beverage-specific alcohol sales per capita (in litres of pure alcohol) were obtained from the Rosstat (Statistics Committee of the Russian Federation) reports. As regards issues of data quality, an earlier study confirmed the reliability of the statistics on violent death for the Soviet period (Wasserman \& Varnik, 1998). In the post-Soviet period, virtually all deaths from external causes are subject to forensic autopsies, which include blood alcohol level inspection and histological examination of organs (Stickly, Leinsalu, Andreew, Razvodovsky, Vagero \& McKee, 2007). The Rosstat causeof-death classification has been undergone several changes over recent decades. In the period 1989-1998 Rosstat used a coding scheme based on ICD-9.

The statistical analysis was performed using the "Statistica" package. It is generally agreed that bivariate correlations between the two raw time-series are spurious, due to common sources of trends and autocorrelation (Norström \& Skog, 2001). Therefore, in order to reduce the risk of obtaining a spurious relation between two variables that have common trends, the trends should be removed by means of a differencing procedure: $\nabla x_{t}=x_{t}-x_{t-1}$ This means analyzing annual changes rather than raw data. The process of removing systematic variation within time-series prior to the examination of potential causal relationships is referred to as "prewhitening". A further step entails the inspection of the cross-correlation function in order to estimate the association 
between the two prewhitened time-series. This technique for undertaking a time-series analysis was suggested by Box and Jenkins, and is often referred to as the ARIMA (autoregressive integrated moving average) model (Box \& Jenkins, 1976). We used this model to estimate the relationship between the time-series beverage-specific alcohol sales per capita and violent mortality rates in this paper.

\section{RESULTS}

According to official statistics, the violent mortality rate increased by $33.8 \%$ (from 165.0 to 220.7 per 100,000 of population), the number of deaths from accidents and injuries increased by $43.0 \%$ (from 94.4 to 135.0 per 100,000 of population), the acute alcohol poisoning death rate increased by $23.8 \%$ (from 23.1 to 28.6 per 100,000 of population), the number of homicides increased by $93.0 \%$ (from 12.9 to 24.9 per 100,000 of population), and the number of suicides decreased by $6.9 \%$ (from 34.2 to 32.2 per 100,000 of population) in Russia from 1980 to 2005 . The trends in violent mortality rates are shown in Figure 1. The time-series fluctuated over the period, decreasing sharply in 1984-1986, beginning to increase in 1987-1988, followed by sharp increases in 1991-1994, a steep decline between 1994 and 1998 and a further increase between 1998 and 2002, before starting to decrease in recent years.

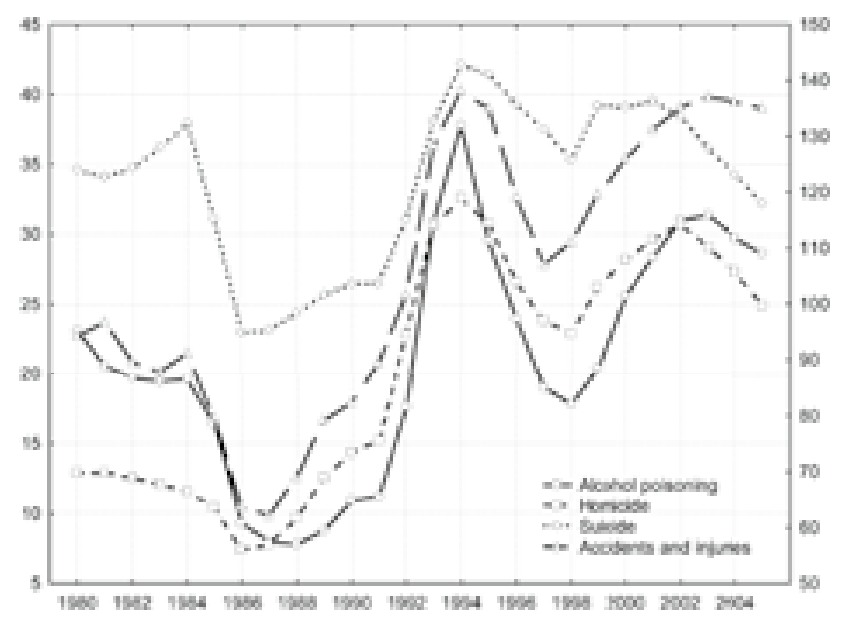

Figure 1. Trends in fatal alcohol poisoning rate (Left scale), homicide rate (Left scale), suicide rate (Left scale) and accidents and injuries mortality rate (Right scale) in Russia between 1980 and 2005.

By the early 1980s, per capita alcohol sales in Russia had reached 10.5 litres, an exceptional level for this country (Figures 2). Per capita sales of state-produced alcohol fell 2.7-fold (from 10.45 to 3.3 litres) between 1984 and 1987, and then increased substantially from 1988 to 1994. Beverage-specific alcohol sales have also fluctuated considerably, but the intensity and direction in development have not been uniform. In particular, between 1984 and 1987 per capita vodka sales decreased 2.5-fold (from 5.56 to 2.2 litres per capita), wine sales decreased 3.9 -fold (from 3.53 to 0.9 litres per capita), and beer sales decreased 1.4-fold (from 1.25 to 0.9 litres per capita). It is important to point out that the structure of overall alcohol sales was variable from one period of time to another. In 1985 the structure of alcohol sales per capita looked as follows: vodka - 54.3\%, wine $-33.8 \%$ and beer $-11.9 \%$, and in 1994: vodka $-80 \%$, wine $-7.2 \%$ and beer $-13.2 \%$.

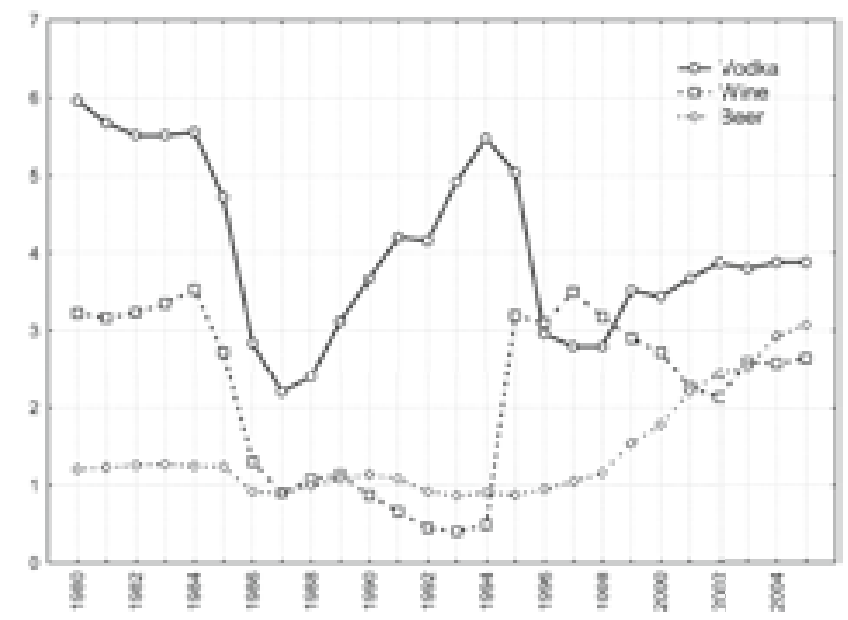

Figure 2. Beverage-specific alcohol sales (in litres) in Russia between 1980 and 2005.

As can be seen from Figures 1-2, there is an S-shape trend in the time-series. This trend was removed by means of first-order differencing procedure. After prewhitening, the cross-correlations between beverage-specific alcohol sales and violent mortality time-series were inspected. The outcome indicated statistically significant cross-correlation between total alcohol/vodka sales per capita and violent mortality, number of deaths from accidents and injuries, fatal alcohol poisoning rate, and number of suicides and homicides at zero and at first lags (Table 1). At the same time, there is no cross-correlation between the level of wine/ beer sales and violent mortality rates. The specification of the bivariate ARIMA model and outcome of the analyses are presented in Table 2. As it can be seen, the estimated effects of total alcohol/vodka sales on violent mortality rates are clearly statistically significant. The analysis suggests that a 1-litre increase in overall alcohol sales would result in a $5 \%$ increase in violent mortality rate and a $4.6 \%$ increase in the number of deaths due to accidents and injuries, a $8.2 \%$ increase in the number of fatal alcohol poisonings, a $4.8 \%$ increase in the number of suicides, and a $5.2 \%$ increase in the number of homicides, while a 1-litre increase in vodka sales is expected to increase the violent mortality rate by $11.3 \%$, the number of deaths due to accidents and injuries by $11.0 \%$, the number of fatal alcohol poisonings by $21.9 \%$, the number of suicides by $9.2 \%$, and the number of homicides by $12.5 \%$. Thus, the current time-series analysis suggests that violent mortality rates tend to be more responsive to changes in spirits sales than to changes in total level of alcohol sales. 
Table 1. The results of cross-correlation analysis between prewhitened time-series. Effects of beverage-specific alcohol sales per capita on violent mortality rates.

\begin{tabular}{|l|c|c|c|c|c|c|}
\hline \multirow{2}{*}{} & \multicolumn{3}{|c|}{ Total alcohol sales } & \multicolumn{3}{c|}{ Vodka sales } \\
\cline { 2 - 8 } & Lag & $r$ & SE & Lag & $r$ & SE \\
\hline Deaths from external causes & $0(1)$ & $0.44(0.59)$ & 0.20 & 0 & 0.77 & 0.20 \\
\hline Accidents and Injuries & $0(1)$ & $0.49(0.55)$ & 0.20 & 0 & 0.80 & 0.20 \\
\hline Suicide & $0(1)$ & $0.53(0.62)$ & 0.20 & 0 & 0.69 & 0.20 \\
\hline Homicide & 1 & 0.41 & 0.20 & 1 & 0.63 & 0.20 \\
\hline Fatal alcohol poisoning & 1 & 0.61 & 0.20 & 0 & 0.67 & 0.20 \\
\hline
\end{tabular}

Table 2. Estimated effects (bivariate ARIMA model) of beverage-specific alcohol sales on violent mortality rates.

\begin{tabular}{|l|c|c|c|c|c|c|}
\hline & \multicolumn{3}{|c|}{ Total alcohol sales } & \multicolumn{3}{c|}{ Vodka sales } \\
\cline { 2 - 7 } & model & estimate & $\mathrm{P}$ & model & estimate & $\mathrm{P}$ \\
\hline Deaths from external causes & $1,1,0$ & 0.050 & 0,001 & $1,1,0$ & 0,113 & 0,000 \\
\hline Accidents and Injuries & $0,1,0$ & 0.046 & 0.004 & $1,1,0$ & 0.110 & 0.000 \\
\hline Suicide & $0,1,0$ & 0.048 & 0.000 & $1,1,0$ & 0.092 & 0.001 \\
\hline Homicide & $0,1,0$ & 0.052 & 0.049 & $0,1,1$ & 0.125 & 0.000 \\
\hline Fatal alcohol poisoning & $0,1,0$ & 0.082 & 0.035 & $1,1,0$ & 0.219 & 0.000 \\
\hline
\end{tabular}

\section{DISCUSSION}

It is widely recognized that overall level of alcohol sales is an important determinant of violent mortality rates (Lester, 1998; Norström \& Ramstedt, 2005). A time-series analysis, based on data for the period 1950-95 and covering 14 European Union countries, suggests that an increase in population drinking had a greater impact on accident mortality in northern Europe than in western/central and southern Europe (Skog, 2001). These findings provided support for the hypothesis that the effect of alcohol on accident mortality rate is stronger in the northern European "spirits" countries, characterized by low per capita consumption, with the bulk of consumption concentrated on a few occasions (binge drinking pattern), or "dry" drinking cultures, than in the southern European wine countries, with a high average consumption more evenly distributed throughout the week, or "wet" drinking cultures. Similarly, the results of a recent study suggest that changes in per capita consumption have a significant impact on injury mortality in six eastern European countries, but that the strength of the association tends to be stronger in countries where intoxication-oriented drinking patterns prevail (Landberg, 2010). In this context it should be noted that the Russian drinking culture combines the explosive drinking pattern of the "dry" drinking culture with the high consumption level of the "wet" drinking culture (Nemtsov \& Razvodovsky, 2008).

Additional development of the idea that alcohol can have detrimental effect on violent mortality in Russia came as a result of individual-level studies. A case-control study in Izhevsk based on proxy information from the families of 1750 men aged 25-54 who died in 2003-2005 reported that periods of heavy drinking were associated with increased risk of death from external causes (Leon et al., 2007). A more recent study of 22,658 forensic autopsies, performed in the Siberian city of Barnaul during the period 1990-2004 has shown that among autopsied men in the 35-69 years age range who were reported to have died from external causes, $76 \%$ of men and $65 \%$ of women were BAC-positive, and $25 \%$ of men and 24\% of women had blood concentrations of alcohol of $4 \mathrm{~g} / \mathrm{l}$ or more (Zaridze, Maximovitch, Lazarev, Igitov, Boroda, Boreham, Boyle, Peto \& Boffetta, 2008).

Understanding the reasons for the dramatic fluctuations in violent mortality rates in Russia over recent decades is very important from a public health perspective. These trends coincide with major political events: the anti-alcohol campaign in the mid-1980s, the political and economic transition following the breakup of the Soviet Union in 1991, and the worsening economic situation associated with financial crisis in 1998. The graphic evidence suggests that spirit drinking and violent death rates are positively related phenomena in Russia: Gorbachev's anti-alcohol campaign in 1985-1988 was associated with a rapid reduction in the level of vodka sales per capita and violent mortality rate, while increasing vodka sales in the transitional period have been linked to higher rates of death from external causes. The coincident trends between the level of vodka sales and the number of deaths from external causes in the mid1980s indicate that a restriction of vodka availability can be considered as an effective measure of violent mortality prevention.

Violent mortality in Russia peaks in 1994/95, and has declined since then. Some authors argue that this reflects increased control over the alcohol market and increased alcohol prices (Nemtsov \& Razvodovsky, 2008), though other commentators are not sure whether the changes have been large enough to account for the downturn (Gavrilova, Semyonova, Evdokushkina \& Gavrilov, 2000). Several researchers also believe that the increase in vodka consumption in 1990s was driven by the psychosocial distress of economic and political reforms and facilitated by the availability of vodka after the abolition of the state alcohol monopoly in January 1992 (Leon \& Shkolnikov, 1998). It seems plausible that the mortality crisis in the mid-1990s was to a large extent due to a changed alcohol consumption structure, whereby $80 \%$ of all alcohol in Russia was consumed in the form of spirits. Wine obviously became less available compared to vodka during the anti-alcohol campaign, after the destruction of most of the vineyards across the country; moreover, in the wake of the Soviet Union's break-up, wine supplies from Moldova, Ukraine, Georgia and other former Soviet republics were cut off.

Before concluding, it is necessary to address some potential limitations of the study that may have affected the outcome. In particular, it should be recognized that unrecorded alcohol accounts for a considerable portion of all alcohol consumed in Russia. Substantial cuts in production and sales, combined with increases in the prices of alcoholic beverages during the anti-alcohol campaign, resulted in the growth of samogon consumption (Nemtsov \& Razvodovsky, 
2008). The same is true for the transitional period after the collapse of the Soviet Union. Following the repeal of the state alcohol monopoly in 1992, the alcohol market became highly fragmented, and the country was flooded by a wave of homemade, counterfeit and imported alcohol of low quality (Nemtsov, 2000). Nor does the current analysis take into account surrogate alcohol, which may have more detrimental effects on health (Stickley, Razvodovsky \& McKee, 2009).

In conclusion, the present study replicates previous findings from other settings which suggest that violent mortality rates tend to be more responsive to changes in distilled spirits sales per capita than to changes in the total level of alcohol sales. The outcomes of this study also provide indirect support for the hypothesis that the profound fluctuations in violent mortality seen in Russia during recent decades may be related to alcohol, as indicated by a close temporal association between number of deaths from external causes and overall alcohol and spirits sales per capita. Assuming that drinking spirits is usually associated with intoxication episodes, these findings support the hypothesis that a binge drinking pattern may intensify the negative role of alcohol in the Russian violent mortality crisis.

\section{REFERENCES}

Box, G.E.P. \& Jenkins, G.M. (1976). Time Series Analysis: forecasting and control. London. Holden-Day Inc.

Bye, E.K. (2008). Alcohol and homicide in Eastern Europe. Homicide Studies, 12, 7-28.

Gavrilova, N.S., Semyonova, V.G., Evdokushkina, G.N. \& Gavrilov, L.A. (2000). The response of violent mortality to economic crisis in Russia. Population Research and Policy Review, 19, 397-419.

Landberg, J. (2008). Alcohol and suicide in Eastern Europe. Drug and Alcohol Review, 27: 361-373.

Landberg, J. (2010). Population drinking and fatal injuries in Eastern Europe: a time-series analysis of six countries. European Addiction Research, 16, 43-52.

Leon, D.A., Chenet, L., Shkolnikov, V.M., Zakharov, S., Shapiro, J., Rakhmanova, G., Vassin, S. \& McKee M. (1997). Huge variation in Russian mortality rates 1984-94: artefact, alcohol, or what? Lancet, 350, 383-88.

Leon, D.A., Saburova, L., Tomkins, S., Andreev, E., Kiyanov, N., McKee, M. \& Shkolnikov, V.M. (2007). Hazardous alcohol drinking and premature mortality in Russia: a population based case-control study. Lancet, 369, 2001-2009.

Leon, D.A. \& Shkolnikov, V.M. (1998). Social stress and the Russian mortality crisis. Journal of the American Medical Association, 79, 790-791.

Lester, D. (1998). Suicide and homicide after the fall of communist regimes. European Psychiatry, 13, 98-100.

Moskalewicz, J., Razvodovsky, Y. \& Wieczorek, P. (2009). East-West disparities in alcohol-related harm within European Union. Paper presented at the KBS Annual Conference, Copenhagen, 1-5 June, 2009.
Nemtsov, A.V. \& Razvodovsky, Y.E. (2008). Alcohol situation in Russia, 1980-2005. Social and Clinical Psychiatry, 2, 52-60.

Nemtsov, A.V. (2000). Estimates of total alcohol consumption in Russia, 1980-1994. Drug and Alcohol Dependence, 58, 133-142.

Nemtsov, A.V. (2002). Alcohol-related human losses in Russia in the 1980s and 1990s. Addiction, 97, 1413-1425.

Nilssen, O., Averina, M., Brenn, T., Brox, J., Kalinin, A. \& Archipovski, V. (2005). Alcohol consumption and its relation to risk factors for cardiovascular disease in the north-west of Russia: the Archangelsk study. International Journal of Epidemiology, 34, 781-788.

Norström, T. \& Ramstedt, M. (2005). Mortality and population drinking: a review of the literature. Drug and Alcohol Review, 24, 537-547.

Norström, T. \& Rossov, I. (1999). Beverage-specific effects on suicide. Nordic Studies of Alcohol and Drugs, 16, 109-18.

Norström, T. \& Skog, O.J. (2001). Alcohol and mortality: methodological and analytical issues in aggregate analysis, Addiction, 96, 5-17.

Pridemore, W.A. \& Chamlin, M.B. (2006). A time-series analysis of the impact of heavy drinking on homicide and suicide mortality in Russia, 1956-2002. Addiction, 101(12), 1719-1729.

Razvodovsky, Y.E. (2000). Structure and dynamics of alcohol-related mortality in Belarus. Alcoholism, 36, 35-43.

Razvodovsky, Y.E. (2001). The association between the level of vodka consumption per capita and violent mortality rate: results of time-series analysis. Adicciones, 13(Suppl. 1), 77-92.

Razvodovsky, Y.E. (2003). Alcohol and mortality crisis in Belarus. Grodno. Medical University Press.

Rehm, J., Sulkowska, U., Manczuk, M., Boffeta, P., Powles, J., Popova, S. \& Zatonski, W. (2007). Alcohol accounts for a high proportion of premature mortality in central and Eastern Europe. International Journal of Epidemiology, 36, 458-67.

Rehm, J., Taylor, B., Patra, J. (2006). Volume of alcohol consumption, pattern of drinking and burden of disease in the European region. Addiction, 101, 1086-95.

Skog, 0.J. (2001). Alcohol consumption and overall accident mortality in 14 European countries. Addiction, 96(Supplement 1), 35-47.

Stickley, A., Leinsalu, M., Andreew, E., Razvodovsky, Y.E., Vagero, D. \& McKee, M. (2007). Alcohol poisoning in Russia and the countries in the European part of the former Soviet Union, 1970-2002. European Journal of Public Health, 17, 444-449.

Stickley, A., Razvodovsky, Y. \& McKee, M. (2009). Alcohol mortality in Russia: A historical perspective. Public Health, 123, 20-26.

Wasserman, D. \& Varnik, A. (1998). Reliability of statistics on violent death and suicide in the former USSR, 1970-1990. Acta Psychiatrica Scandinavica, 394(Supplement), 34-41.

Zaridze, D., Maximovitch, D., Lazarev, A., Igitov, V., Boroda, A., Boreham, J., Boyle, P., Peto, R. \& Boffetta, P. (2008). Alcohol poisoning is a main determinant of recent mortality trends in Russia: evidence from a detailed analysis of mortality statistics and autopsies. International Journal of Epidemiology, 38, 143-153. 
